\title{
Isolation and Characterization of Detergent Compatible Alkaline Protease Producing Bacillus Subtilis AP0-1
}

\author{
Ami Vishnusinh Sayaniya and Prittesh Patel* \\ CG Bhakta Institute of Biotechnology, Uka Tarsadia University, India
}

*Corresponding author: Prittesh Patel, Assistant Professor, C. G. Bhakta Institute of Biotechnology, Uka Tarsadia

University, Bardoli, Maliba Campus, Surat, Gujarat, India

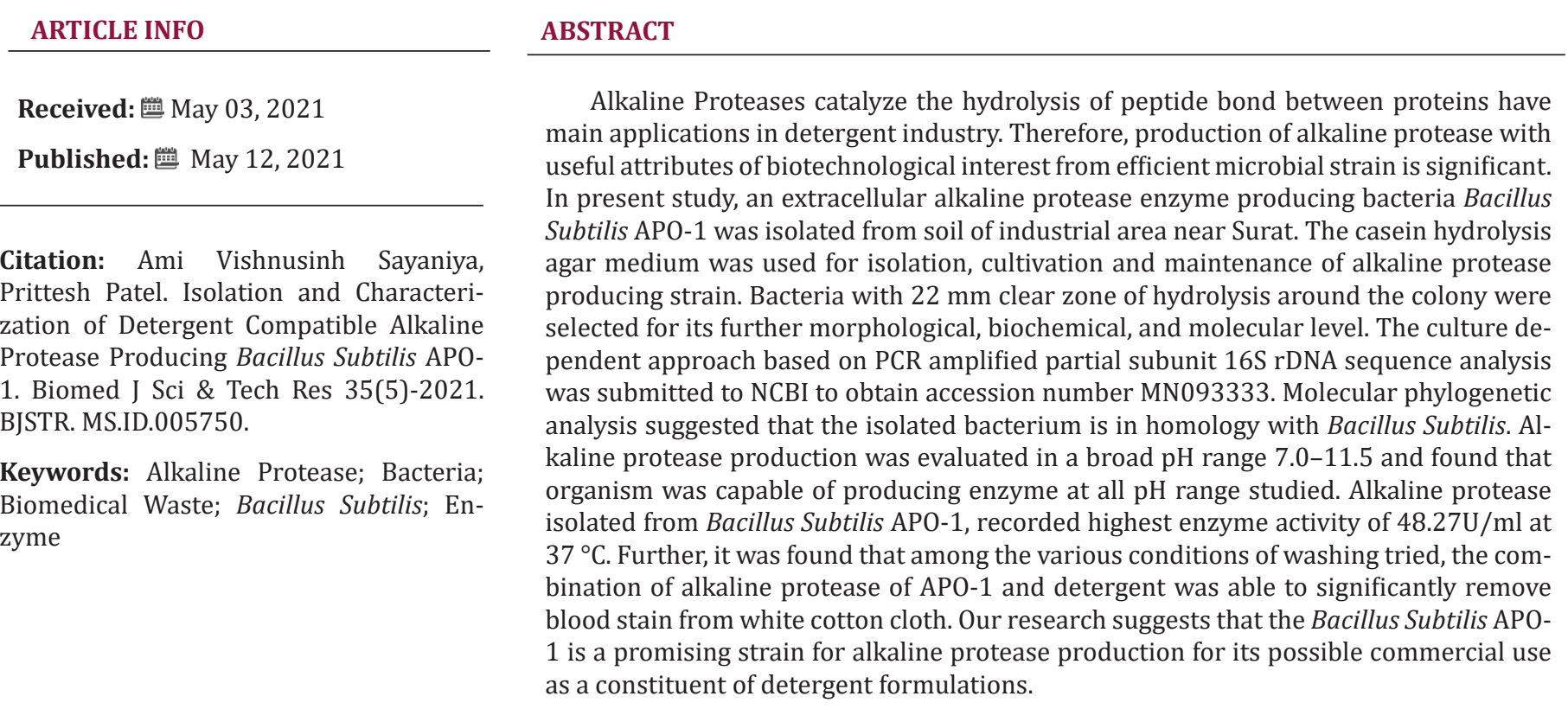

\section{Introduction}

Proteases are a complex group omnipresent enzyme in nature which catalyze the cleavage of the peptide bonds among the amino acid residues in different proteins; has a place with a class of hydrolases with massive physiological and commercial importance. In light of their acid-base behavior, proteases are characterized in to three groups, that is, acid, neutral and alkaline proteases. Acid proteases perform best at $\mathrm{pH}$ range of 2.0-5.0 and are mostly produced by fungi. Proteases with $\mathrm{pH}$ optima in the range of 7.0 or around are called neutral proteases. Neutral proteases are predominantly produced by plants. While proteases optimum activity at $\mathrm{pH}$ range of 8 or more are classified as alkaline proteases [1]. Though categorized into three classes on the bases of mode of action, alkaline proteases alone comprise about $89 \%$ of the entire protease market because of its broad applications in detergents, leather processing, protein recovery, meat tenderization, food industry, pharmaceuticals, and bioremediation [2]. Alkaline proteases, with good activity and stability in high alkaline range, are interesting for several bioengineering and biotechnological applications. However, their predominant application is in the detergent industry [3]. Since the pH of laundry detergents is in the range of 9.0-12.0, alkaline proteases are utilized in detergent formulations, with other hydrolytic enzymes, as additives to work with the breakdown and release of proteins $[4,5]$.

Many microorganisms produce proteases; however, the enormous extent of commercial alkaline proteases is generally gotten from Bacillus sp., as a result of its capacity to secrete large 
amount of alkaline proteases having significant proteolytic activity, stability at high temperature and wide range of $\mathrm{pH}$. Number of studies has been reported on alkaline protease production by Bacillus like Bacillus cereus [6], Bacillus infantis [7], Bacillus subtilis [8], Bacillus pumilus [9] etc. Microbial proteases, especially from Bacillus subtilis are the most widely exploited industrial enzymes [10]. Advances in analytical methods have exhibited that proteases direct profoundly explicit specific and selective modifications of proteins, for example, activation of zymogenic types of enzymes by limited proteolysis, blood coagulating and lysis of fibrin clusters, and processing and transport of secretory proteins across the membranes [11]. Removal of proteinaceous stains like blood, milk, egg, grass and chocolate is very difficult utilizing traditional detergent approach. Vishalakshi et al. reported the successful removal of blood stain by alkaline protease from Streptomyces gulbargensis [12]. Notwithstanding, removal of such stain is accomplished by utilizing alkaline proteases $[13,14]$. The alkaline protease enzymes are acquiring a massive significance in the detergent industries because of their inherent capacity to sustain the broad $\mathrm{pH}$ with effective specificity in various cleanser detergent additives. The latest trend is to utilize detergent-compatible proteases that are steady over a wide $\mathrm{pH}$ range. This enzyme also has inherent benefits and cost-effectiveness over the ordinary synthetic catalysts. The finding for detergent-compatible proteases with better properties is a continuous exercise. The present study was initiated to with the aim to collect soil sample from dump side near Surat for the isolation of alkaline protease producing alkaliphilic bacteria and qualitative and quantitative analysis of protease production. Further as an application part work was intended for blood stain removal and detergent compatibility of crude enzyme.

\section{Material and Methods}

\section{Isolation of Alkaline Protease Producing Bacteria}

Soil sample were collected from Surat dump side area below 5-6 $\mathrm{cm}$ depth and stored in sterile plastic bags and taken to the lab aseptically. Isolation of alkaline protease producing alkaliphilic bacteria was carried out using alkaline solid agar medium contained glucose ( $5 \mathrm{~g} / \mathrm{L})$, yeast extract ( $3 \mathrm{~g} / \mathrm{L})$, peptone ( $5 \mathrm{~g} / \mathrm{L})$, and agar (20 $\mathrm{g} / \mathrm{L}$ ), (pH 7 to 10.5) in addition to $20 \%$ (w/v) casein powder, as an indicator of alkaline protease production [15]. $1 \mathrm{gm}$ of soil sample was weighted and serial dilution from 10-1 to 10-6 was carried out. $0.1 \mathrm{ml}$ of each aliquot was spread on above mentioned media plate and incubated at $37{ }^{\circ} \mathrm{C}$ for 24 to 48 hours. The zone of hydrolysis was noted on all the $\mathrm{pH}$ range evaluated and the colony showing highest zone of inhibition was selected for further study. The colony was grown on casein agar plate repeatedly and preserved on Nutrient agar slant at $4^{0} \mathrm{C}$ for further study.

\section{Morphological and Biochemical Characterization}

The morphological characterization of the isolated bacterium was performed through Gram staining. The different biochemical tests were performed to determining the metabolic activities of bacteria are indole production test, methyl red test, Voges Proskauer test, urea hydrolysis test, hydrogen sulphide production test, nitrate reduction test, ammonia production test, citrate utilization test, phenylalanine deamination test, triple sugar iron agar test, starch hydrolysis test, lipid hydrolysis test, casein hydrolysis test, hemolysin production test, oxidase test, catalase test, gelatin hydrolysis test, dehydrogenase test, sugar utilization test.

\section{Molecular Identification and Phylogenetic Analysis}

The genomic DNA was isolated according to Sambrook [16]. Total genomic DNA was extracted were used for PCR amplification of $16 \mathrm{~S}$ rDNA in combination with the following sets of universal primers 1) 8F AGA GTT TGA TCM TGG CTC AG and 2) 1492R CGG TTA CCT TGT TAC GAC TT). DNA sequencing of PCR amplicon was carried out with 8F \& 1492R primers using BDT v3.1 Cycle sequencing kit on ABI 3730xl Genetic Analyzer. The PCR amplified products were then subjected to 16 s rRNA sequencing for molecular identification. Analyses of $16 \mathrm{~s}$ rDNA gene sequence was performed with bioinformatics tool BLAST. Sequences were aligned against the database of National Centre for Biotechnology Information (www. ncbi.nlm.nih.gov). The sequences were aligned using multiple sequence alignment program CLUSTAL W followed by MEGA X for phylogenetic analysis. The percentage of replicate trees in which the associated taxa clustered together in the bootstrap test $(1000$ replicates) were shown next to the branches and phylogenetic tree generated with Neighbor-joining method.

\section{pH Stability}

Solid agar medium similar as isolation media was used to evaluate the ability of Bacillus Subtilis APO-1 to produce alkaline protease at different $\mathrm{pH}$ value i.e 7, 8, 9, 10, 11 and 11.5. 24-hour active culture was centrally inoculated on solid agar medium and plates were incubated at $37{ }^{\circ} \mathrm{C}$. Alkaline protease production was observed after 48 hours.

\section{Protease Activity Assay}

$200 \mu \mathrm{l}$ of $24 \mathrm{hr}$ old bacterial culture was inoculated in $60 \mathrm{ml}$ casein hydrolysate medium and kept in incubator at $37^{\circ} \mathrm{C}$. After 48-hour incubation, the bacterial culture was centrifuged at 3000 rpm for $12 \mathrm{~min}$ and the supernatant was utilized for alkaline protease enzyme assay. Protease action was dictated by addition of $0.65 \%$ casein in $50 \mathrm{mM}$ phosphate buffer ( $\mathrm{pH} 7.5$ ) as substrate. $1 \mathrm{ml}$ enzyme and casein substrate was incubated at $37^{\circ} \mathrm{C}$ for 20 min. To stop the reaction $2.5 \mathrm{ml}$ Trichloroacetic acid was utilized. 
One unit of protease activity was characterized as the 0.1 unit increase in optical density upon $1 \mathrm{hr}$ incubation. At that point solution was filtered by utilizing a $0.45 \mu \mathrm{m}$ filter and $2 \mathrm{ml}$ of filtrate was mixed with $2.5 \mathrm{ml}$ of $500 \mathrm{mM}$ sodium carbonate and incubated for $20 \mathrm{~min}$ at $37^{\circ} \mathrm{C}$. After that, $0.5 \mathrm{ml}$ of Folin Ciocalteu's reagent was added, and the absorbance was measured at $660 \mathrm{~nm}$ utilizing Spectrophotometer [17]. The measure of protease produced by bacteria was assessed and expressed in microgram of tyrosine released under standard test conditions.

\section{Stain Removal and Detergent Compatibility of Bacteria Enzyme}

Activity of protease enzyme as a detergent additive was analyzed through different combinations of treatment on blood sample-stained cloth. Four white cotton clothes $(5 \times 5 \mathrm{~cm})$ with blood separately treated in flasks as followings.

a) Blood-stained cloth treated with $(2 \mathrm{ml})$ distilled water.

b) Blood-stained cloth treated with $(1 \mathrm{ml})$ distilled water+ $1 \mathrm{ml}$ detergent $(0.01 \mathrm{mg} / \mathrm{ml})$.

c) Blood-stained cloth treated with $(2 \mathrm{ml})$ enzyme solution.

d) Blood-stained cloth treated with $(1 \mathrm{ml})$ detergent $(0.01 \mathrm{mg} / \mathrm{ml})$ $+(2 \mathrm{ml})$ enzyme solution.

All four flasks were incubated at $37^{\circ} \mathrm{C}$ for $15 \mathrm{~min}$. All four flasks were incubated at $37^{\circ} \mathrm{C}$ for $15 \mathrm{~min}$. After incubation, cloth pieces were taken out, washed with normal water and dried. Visual assessment of cloth pieces displayed the impact of enzymes in removal of blood stains (Figure 2). Untreated cloth pieces stained with blood were taken as control.

\section{Result and Discussion}

\section{Isolation of Alkaline Protease Producing Bacteria}

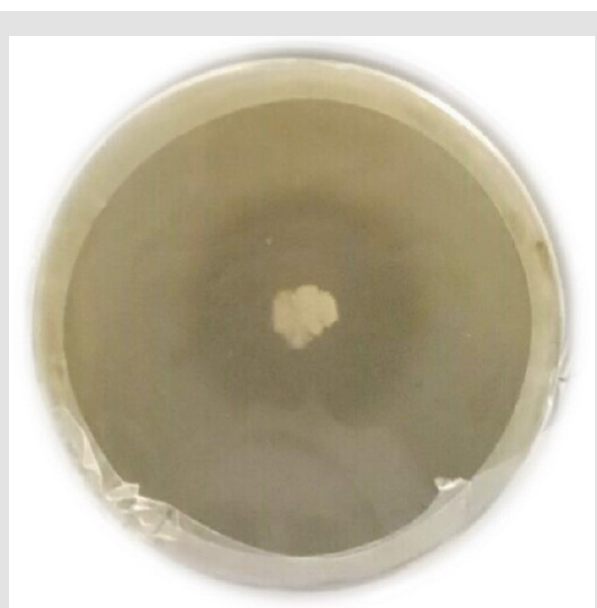

Figure 1: Zone of casien solubiliztion by Bacilli subtilis APO-1 isolated from industrial soil sample collected from Surat.
In the present study, an attempt was made to isolate most efficient extracellular alkaline protease producing bacteria from soil sample from industrial field present on outskirts of Surat region Gujarat. Based on its Casein hydrolysate activity through zone of solubilization, one potential isolate APO-1 was selected for further study (Figure 1). Bacterial colony appeared on the casein agar plates were observed to be $2-3 \mathrm{~mm}$ in diameter, lobate, flat and white and exhibited around $22 \mathrm{~mm}$ clear zone of hydrolysis around the colony. The isolate APO- 1 was stored in $40 \%$ glycerol at 4 으 for further experimental studies.

\section{Morphological, Biochemical and Molecular Characteri- zation}

The results of morphological characterization reveal that Bacillus Subtilis APO-1 was gram-positive, facultative anaerobe, motile and short rod. An extensive biochemical characterization of APO- 1 was carried out and is tabulated in Table 1. Genomic DNA of the isolate APO-1 was amplified and obtained the product length was $1050 \mathrm{bp}$. The PCR amplification using forward primer and reverse primer generated a single band amplicon size of $1 \mathrm{~kb}$ on 1 $\%$ agarose gel (Figure 2).

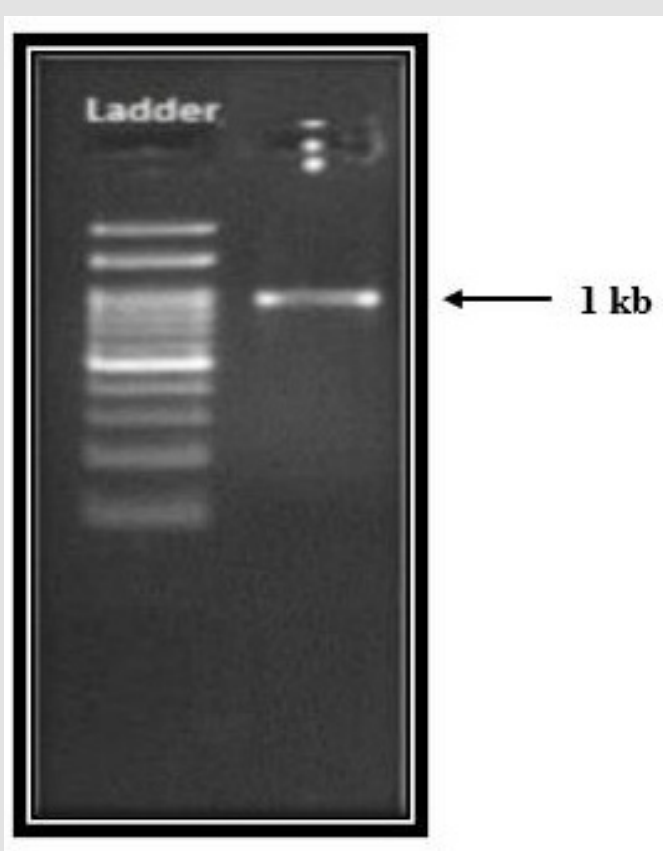

Figure 2: PCR amplification of $16 \mathrm{~S}$ rDNA gene of the isolated bacterium.

\section{Morphological, Biochemical and Molecular Characteri- zation}

The results of morphological characterization reveal that Bacillus Subtilis APO-1 was gram-positive, facultative anaerobe, motile and short rod. An extensive biochemical characterization of APO- 1 was carried out and is tabulated in Table 1. Genomic DNA of the isolate APO-1 was amplified and obtained the product length 
was $1050 \mathrm{bp}$. The PCR amplification using forward primer and reverse primer generated a single band amplicon size of $1 \mathrm{~kb}$ on 1 $\%$ agarose gel (Figure 2).

Neighbor-joining phylogenetic tree showing the relatedness between the 16S rRNA gene sequence of the isolated bacterium and their closest relative sequences retrieved from microbial databases (Figure 3). The phylogenetic tree constructed by the neighbor-joining method indicated that the isolate presented

Table 1: Biochemical Characterization of Bacilli subtilis APO-1. on separate cluster. The numbers in parentheses correspond to the accession number. The optimal tree with the sum of branch length $=0.23477701$ is shown. The evolutionary distances were computed using the Maximum Composite Likelihood method and are in the units of the number of base substitutions per site. The analysis involved 11 nucleotide sequences. That is, fewer than $5 \%$ alignment gaps, missing data, and ambiguous bases were allowed at any position. All positions with less than 95\% site coverage were eliminated. Evolutionary analyses were conducted in MEGA X.

\begin{tabular}{|c|c|c|c|}
\hline Biochemical Test & Result & Biochemical Test & Result \\
\hline Glucose & Positive & Maltose & Negative \\
\hline Xylose & Positive & Sucrose & Positive \\
\hline Lactose & Negative & Fructose & Negative \\
\hline Indole production & Positive & Starch hydrolysis test & Positive \\
\hline MR test & Positive & Lipid hydrolysis test & Positive \\
\hline VP test & Positive & Casein hydrolysis test & Positive \\
\hline Urea hydrolysis test & Negative & Hemolysin test & Negative \\
\hline H2S Production test & Negative & Oxidase test & Positive \\
\hline Nitrate reduction test & Positive & Catalase test & Positive \\
\hline Ammonia production test & Negative & Gelatine hydrolysis test & Positive \\
\hline Citrate utilization test & Positive & Dehydrogenase test & Positive \\
\hline Phenyl alanine test & Negative & & \\
\hline
\end{tabular}

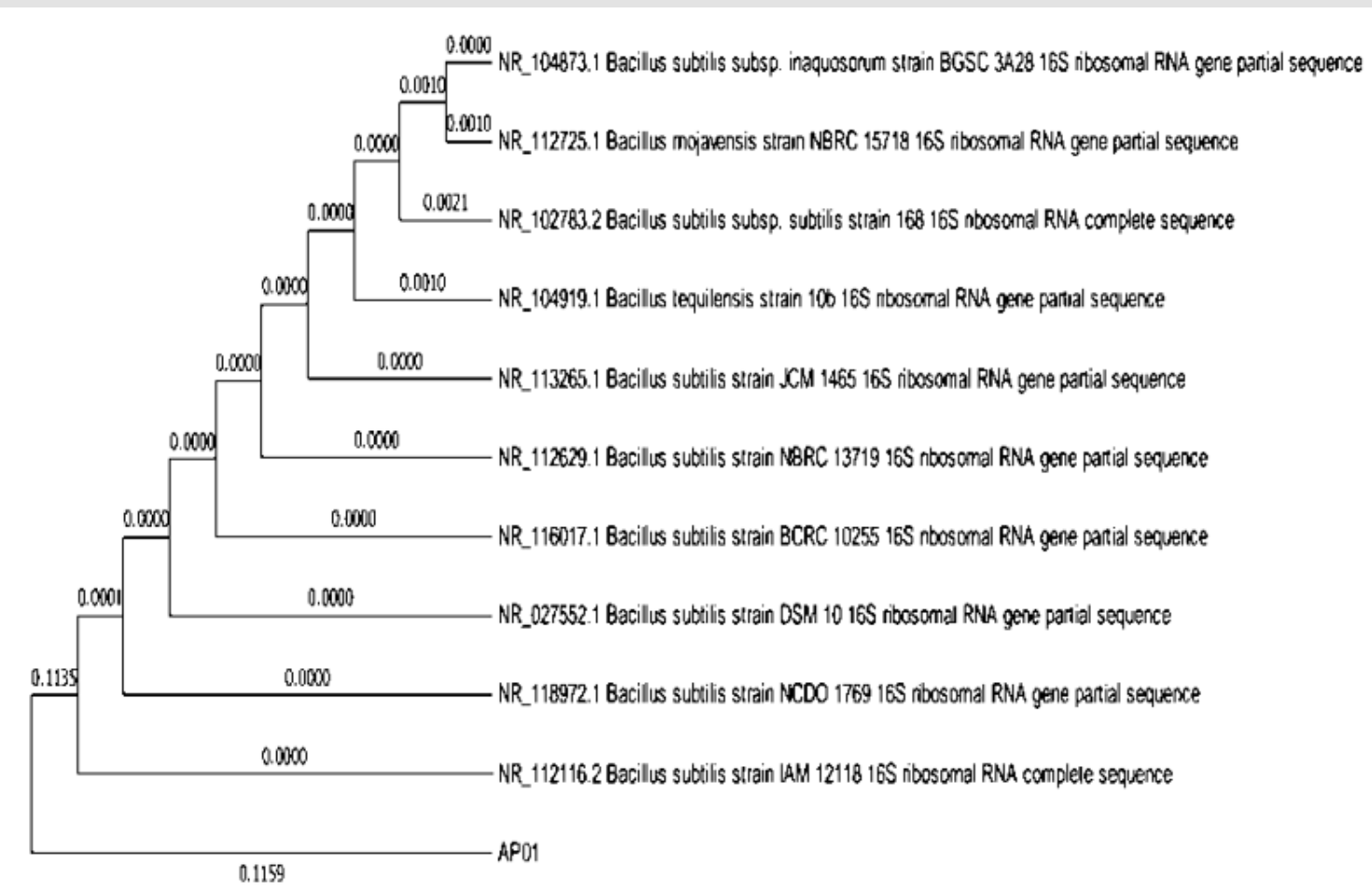

Figure 3: Phylogenetic tree generated with Neighbour-joining method. The percentage of replicate trees in which the associated taxa clustered together in the bootstrap test (1000 replicates) were shown next to the branches and phylogenetic tree. 


\section{pH Stability}

$\mathrm{pH}$ stability is an essential characteristic for the use of alkaline protease as detergent additives. In our study protease of APO- 1 was found active in broad $\mathrm{pH}$ range 7.0-11.5. Organism APO-1 grown well on all the $\mathrm{pH}$ studied with clear zone of casein solubilization.

\section{Protease Activity Assay}

When the protease is testing digests casein, the amino acid tyrosine is liberated along with other amino acids and peptide fragments. The amount of protease produced was estimated and expressed in microgram of tyrosine released under standard assay conditions. In this assay, casein acts as a substrate. Folin's reagent primarily reacts with free tyrosine to produce a blue-colored chromophore which is quantifiable and measured as an absorbance value on the spectrophotometer. The more tyrosine that is released from casein, the more the chromophores are generated and the stronger the activity of the protease. From the standard curve the activity of protease samples can be determined in terms of Units, which is the amount in micromoles of tyrosine equivalents released from casein per minute. Micromoles of tyrosine divided by time in minutes yields measurement of protease activity called "units". The result showed in the micromoles of tyrosine liberated during this particular proteolytic reaction. Alkaline protease activity estimated in culture filtrate of APO- 1 with $0.5,0.7$ and $1 \mathrm{ml}$ of enzyme solution was $32.11 \mathrm{U} / \mathrm{ml}, 40.20 \mathrm{U} / \mathrm{ml}$, and $48.27 \mathrm{U} / \mathrm{ml}$, respectively (Table 2).

Table 2: Extracellular enzyme production by Bacilli subtilis APO1.

\begin{tabular}{|c|c|c|c|}
\hline Isolate & $\begin{array}{c}\text { Various amount of } \\
\text { enzyme solution } \\
(\mathbf{m l})\end{array}$ & $\begin{array}{c}\text { Conc. } \\
(\boldsymbol{\mu g} / \mathbf{m l})\end{array}$ & $\begin{array}{c}\text { Enzyme } \\
\text { Unit/ml }\end{array}$ \\
\hline \multirow{2}{*}{$\begin{array}{c}\text { Bacilli subtilis } \\
\text { APO-1 }\end{array}$} & 1 & 183.5 & 48.27 \\
\cline { 2 - 4 } & 0.7 & 175.9 & 40.2 \\
\cline { 2 - 4 } & 0.5 & 160.9 & 32.11 \\
\hline
\end{tabular}

\section{Stain Removal and Detergent Compatibility of Crude} Enzyme

Cleansing property of protease was checked for the removal of blood stain from the white cotton cloth by mixing the enzyme with detergent solution. Additionally, correlation was established with the commercially available detergents, and results show that introduction of enzyme to the detergent increases the washing performance of the detergent. It was clearly illustrated the cleaning action of APO-1 protease, blood stain was not removed completely with detergent alone, while the mixture of enzyme with commercial detergent removes the blood stain more efficiently. Reflectance measurement showed that about $85-90 \%$ blood stain was removed (Figure 4).

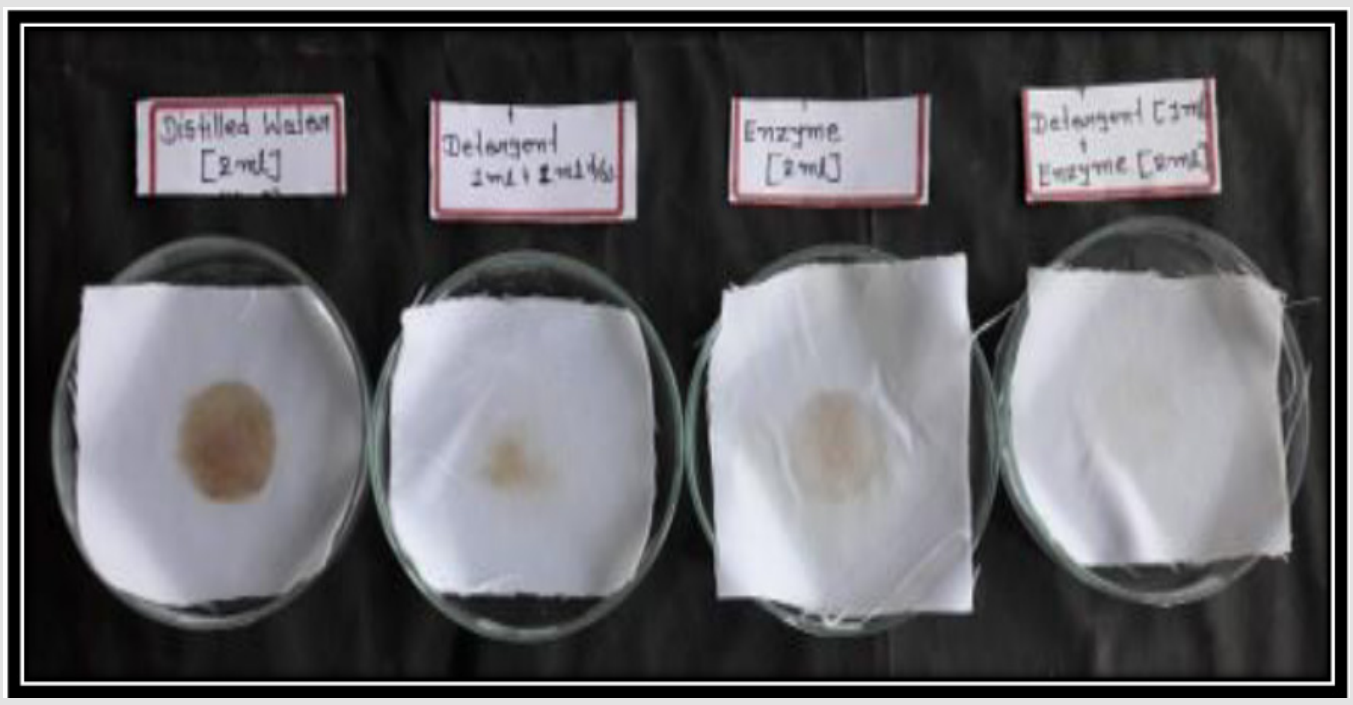

Figure 4: Visual examination of cloth pieces exhibited the effect of enzymes in removal of blood stains.

\section{Discussion}

In this study, the microorganism Bacillus Subtilis APO-1 isolated from the soil is evaluated for the alkaline protease production. The protease from this organism is active at alkaline $\mathrm{pH}$ so this is alkaline protease. Alkaline proteases are a physiologically and commercially important group of enzymes used primarily as detergent additives. They play a specific catalytic role in the hydrolysis of protein. The capacity of Bacillus strains to produce large amounts of the alkaline protease with high activity recognized them as significant sources of commercial proteases and in this way are excellent candidates for large scale proteases production. Numerous scientists revealed the production of proteases from Bacillus species and their applications in detergent industries [18]. El-Safey and AbdulRaouf worked on production, purification and characterization of extracellular protease enzyme isolated from B. Subtilis and studied the optimum conditions for maximum protease activity which is 
comparable to our study [19]. In our study the strain APO-1 has been identified as Bacillus Subtilis on the basis of morphological and biochemical and molecular characterization. Casein was used as the substrate in nutrient agar medium for qualitative analysis and showed maximum zone of activity after overnight incubation. Protease of APO-1 was found active in broad pH range 7.0-11.5. These findings are in accordance with earlier reports showing the optimum pH 10.0-10.5 reported by Banik et al. [20]. The similar results were reported by Genckal and Tari who found novel alkaline protease from alkalophilic Bacillus sp L21 showed optimal stability at pH 11.0 [21].

The protease form Bacillus Subtilis APO-1 gave better result in removal of blood stain from cotton cloth as detergent additives. Numerous investigations exhibited the applicability and suitability alkaline protease in commercial detergents, which served an amazing execution to speed up the cleaning capacity of detergents. Shaikh et al (2018) reported the detergent-compatible alkaline protease from the bacterial strain Bacillus sp. APP-07 isolated from soil [22]. Haddar et al. also reported detergent-compatible protease enzyme from Bacillus mojavensis A21, which exhibited excellent stability in the presence of solid and liquid detergents [3]. Mala et al. also reported biocompatibility of alkaline protease from Bacillus sps. with commercial detergents such as Kite, Tide and Aerial and reported that the enzyme showed $70 \%$ activity even after 3 hours [23].

\section{Conclusion}

This is first time we are reporting the strain of Bacillus Subtilis capable of producing alkaline protease at $\mathrm{pH} 11.5$. This feature is promising for further detail characterization for its large-scale production. The alkaline protease form Bacillus Subtilis APO-1 presented excellent stain removal potential in combination with detergent solution. The blood stain was completely removed from the cotton fabric and might serve several possible applications as detergent additives.

\section{Acknowledgment}

None.

\section{Conflict of Interest}

None.

\section{References}

1. Gupta R, Beg Q, Khan S, Chauhan B (2002) An overview on fermentation, downstream processing and properties of microbial alkaline proteases. Applied microbiology and biotechnology 60(4): 381-395.

2. Mukherjee AK, Adhikari H, Rai SK (2008) Production of alkaline protease by a thermophilic Bacillus Subtilis under solid-state fermentation (SSF) condition using Imperata cylindrica grass and potato peel as low-cost medium: characterization and application of enzyme in detergent formulation. Biochemical Engineering Journal 39(2): 353-361.
3. Haddar A, Agrebi R, Bougatef A, Hmidet N, Sellami-Kamoun A, Nasri M (2009) Two detergent stable alkaline serine-proteases from Bacillus mojavensis A21: purification, characterization and potential application as a laundry detergent additive. Bioresource Technology 100(13): 33663373.

4. Jain D, Pancha I, Mishra SK, Shrivastav A, Mishra S (2012) Purification and characterization of haloalkaline thermoactive, solvent stable and SDS-induced protease from Bacillus sp.: a potential additive for laundry detergents. Bioresource Technology 115: 228-236.

5. Joshi S, Satyanarayana T (2013) Characteristics and applications of a recombinant alkaline serine protease from a novel bacterium Bacillus lehensis. Bioresource technology 131: 76-85.

6. Lakshmi B, Kumar DM, Hemalatha K (2018) Purification and characterization of alkaline protease with novel properties from Bacillus cereus strain S8. Journal of Genetic Engineering and Biotechnology 16(2): 295-304.

7. Saggu SK, Mishra PC (2017) Characterization of thermostable alkaline proteases from Bacillus infantis SKS1 isolated from garden soil. PloS one 12(11): e0188724.

8. Shafique T, Shafique J, Zahid S, Kazi M, Alnemer O, et al. (2021) Screening, selection and development of Bacillus Subtilis apr-IBL04 for hyper production of macromolecule alkaline protease. Saudi Journal of Biological Sciences 28(2): 1494-1501.

9. Özçelik B, Aytar P, Gedikli S, Yardımcı E, Çalışkan F, et al. (2014) Production of an alkaline protease using Bacillus pumilus D3 without inactivation by SDS, its characterization and purification. Journal of enzyme inhibition and medicinal chemistry 29(3): 388-396.

10. Oda K (2012) New families of carboxyl peptidases: serine-carboxyl peptidases and glutamic peptidases. The Journal of Biochemistry 151(1): 13-25.

11. Rao MB, Tanksale AM, Ghatge MS, Deshpande VV (1998) Molecular and biotechnological aspects of microbial proteases. Microbiology and molecular biology reviews 62(3): 597-635.

12.Vishalakshi N, Lingappa K, Amena S, Prabhakar M, Dayanand A (2009) Production of alkaline protease from Streptomyces gulbargensis and its application in removal of blood stains.

13. Raj A, Khess N, Pujari N, Bhattacharya S, Das A, et al. (2012) Enhancement of protease production by Pseudomonas aeruginosa isolated from dairy effluent sludge and determination of its fibrinolytic potential. Asian Pacific Journal of Tropical Biomedicine 2(3): S1845-S1851.

14. Chaudhari S, Chaudhari S, Khobragade R, Deshmukh A (2013) Studies on production of alkaline proteases from Bacillus species and its application in detergent industry. DAV International Journal of Science 2: 44-48.

15. Sundararajan S, Kannan CN, Chittibabu S (2011) Alkaline protease from Bacillus cereus VITSN04: potential application as a dehairing agent. Journal of bioscience and bioengineering 111(2): 128-133.

16. Sambrook J, Fritsch EF, Maniatis T (1989) Molecular cloning: a laboratory manual. Cold spring harbor laboratory press, United States.

17. Das G, Prasad M (2010) Isolation, purification \& mass production of protease enzyme from Bacillus Subtilis. Int Res J Microbiol 1(2): 26-31.

18. Ibrahim AS, Al-Salamah AA, Elbadawi YB, El-Tayeb MA, Ibrahim SSS (2015) Production of extracellular alkaline protease by new halotolerant alkaliphilic Bacillus sp. NPST-AK15 isolated from hyper saline soda lakes. Electronic Journal of Biotechnology 18(3): 236-243.

19. El-Safey E, Abdul-Raouf U (2004) Production, purification and characterization of protease enzyme from Bacillus Subtilis. In: International Conferences for Development and the Environment in the Arab World, Assiut Univ 2: 23-25. 
20. Banik RM, Prakash M (2004) Laundry detergent compatibility of the alkaline protease from Bacillus cereus. Microbiological research 159(2): 135-140.

21. Gençkal H, Tari C (2006) Alkaline protease production from alkalophilic Bacillus sp. isolated from natural habitats. Enzyme and Microbial Technology 39(4): 703-710.

\section{ISSN: 2574-1241}

DOI: 10.26717/BJSTR.2021.35.005750

Prittesh Patel. Biomed J Sci \& Tech Res

(C) (P) This work is licensed under Creative Submission Link: https://biomedres.us/submit-manuscript.php
22. Shaikh I, Dixit P, Shaikh T (2018) Purification and characterization of alkaline soda-bleach stable protease from Bacillus sp. APP-07 isolated from Laundromat soil. Journal of Genetic Engineering and Biotechnology 16(2): 273-279.

23. Mala M, Srividya S (2010) Partial purification and properties of a laundry detergent compatible alkaline protease from a newly isolated Bacillus species Y. Indian journal of microbiology 50(3): 309-317.

\begin{tabular}{ll} 
BIOMEDICAL & Assets of Publishing with us \\
RESEARCHES & - Global archiving of articles \\
\hline Immediate, unrestricted online access \\
- Rigorous Peer Review Process
\end{tabular}

